\title{
Research on the teaching method based on cultivating interest
}

\section{Yang Zheng, Jiangping Zheng}

Yang Zheng, Jiangping Zheng, "Research on the teaching method based on cultivating interest," Proc. SPIE 10452, 14th Conference on Education and Training in Optics and Photonics: ETOP 2017, 1045238 (16 August 2017); doi: $10.1117 / 12.2270961$

SDIE Event: 14th Conference on Education and Training in Optics and Photonics, ETOP 2017, 2017, Hangzhou, China 


\title{
Research on the teaching method based on cultivating interest
}

\author{
Zheng Yang, Zheng Jiangping \\ College of opto-electronic engineering, chang chun university of science and technology, Chang \\ Chun, Jilin 130022, China
}

\begin{abstract}
It is a very effective studying method to cultivate the students' interest, but the key is how to make the students interested in the content of the learning. This paper researches a teaching method of the reversal mode. The method is to let a student to play the role of the teacher, however, the teacher is to be a student. It can make the students get knowledge very well by themselves and give full play to their potential and the subjective initiative. Compared with the previous conventional teaching, the students master the knowledge points more clearly. This method is real and effective, we get good results through a semester of teaching.
\end{abstract}

Key words: education; optics; teaching method; interest

\section{INTRODUCTION}

Learning interest is the desire to explore the unknown a tendency, which is the most active and the most active factors in the learning motivation. As an important part of non-intelligence factors, learning interest can significantly improve the efficiency of intellectual activities, inspire students' thirst for knowledge, and improve the students' learning enthusiasm $\left.{ }^{[1}\right]$, for the realization of lifelong learning and sustainable development to provide the inexhaustible power. Learning interest is a people tend to know, the psychological characteristics of research to get some knowledge ${ }^{[2]}$, it is people's knowledge of a kind of inner strength. Develop the students' interest in the teaching process is extremely important.

\section{THE BENEFITS OF CULTIVATING INTEREST}

\subsection{Strengthen college students' sense of achievement}

Learning interest can enhance students a sense of achievement, which is equivalent to an energy since the incentive system by its start learning system. In this since the incentive system, and end when the learning process, learners from certain mental satisfaction (e.g., knowledge is cheerful, self-confidence of satisfaction, a sense of achievement, etc.) as a reward the system generated inside the positive feedback, again into the intrinsic motivation, enhance the motive force, for cycle operating system provide a steady stream of energy ${ }^{[3]}$. Internal motive in activities have shown high achievement, perseverance and creativity, high energy, high self-esteem and a sense of achievement in the cognitive activities of interest are deeply experience the excitement, joy, surprise, the movement of emotions, etc.

14th Conference on Education and Training in Optics and Photonics: ETOP 2017, edited by Xu Liu,

Xi-Cheng Zhang, Proc. of SPIE Vol. 10452, 1045238 - @ 2017 ICO, IEEE, OSA, SPIE

CCC code: $0277-786 X / 17 / \$ 18 \cdot$ doi: $10.1117 / 12.2270961$ 


\subsection{Improve college students' subjectivity}

Interest can promote the individual with a positive attitude to participate in learning activities, move to construct their own knowledge structure, lay solid foundation for the all-round development. Strong interest in learning, can drive individuals to one thousand ways for problem solving ways and means, in the process of problem solving develop strong character of will, to strengthen the essence of subject. Learning interest is the main activity of undergraduate. Only stimulate students' interest in learning, can make their psychological learning process, the process of learning activities to enter the mental structure of main body and object, main body will take the initiative to adjust, transform, enrich their own psychological structure.

\subsection{Improve college students' creativity}

Learning interest can be optimized process of mental activity. Brain science research also suggests that strong interest in learning can make about the study of nerve cells in the brain in a highly excited state, whereas irrelevant part highly suppressed, the relevant part of the nerve fiber channel will keep clear of height. College students once formed a stable interest in learning, and combining the interest and life ideal, will produce a powerful spiritual force, improve the enthusiasm and creativity of the individual learning practice.

\section{CULTIVATE INTEREST METHOD}

\subsection{Strengthen the experiment teaching}

Applied optics is a science based on experiment, we can change teaching method to improve the enthusiasm of students through the experiment of vivid interesting. It can induce the students' inspiration and stimulate their curiosity and interest. Some simple demonstration experiment can be set up by the students to increase their learning enthusiasm.
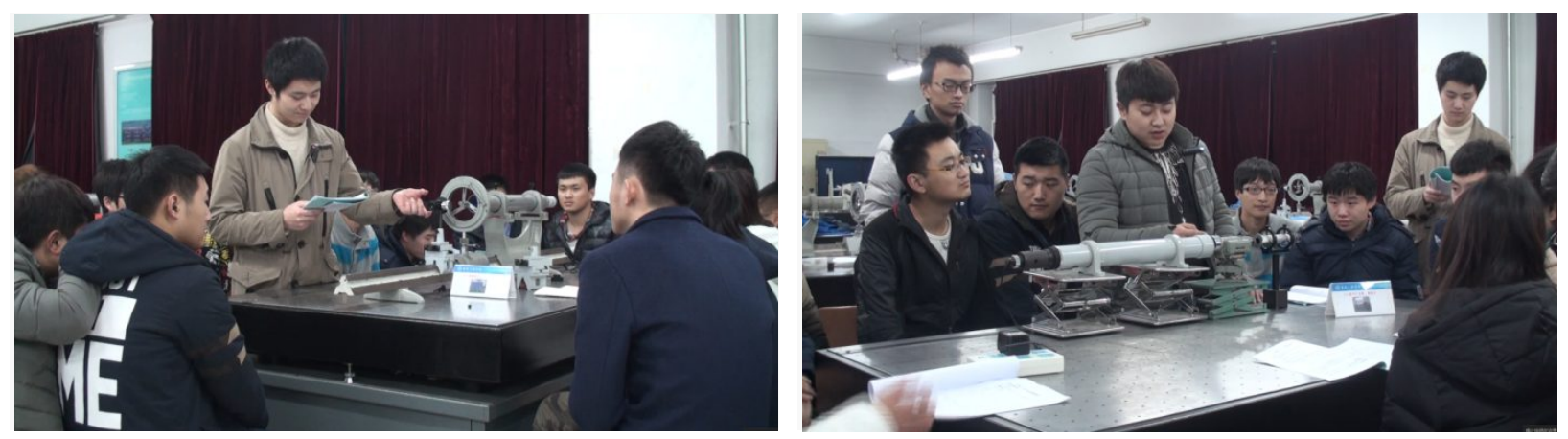

Fig.1 Students independent experiment

Try to let some student who has abilities to be a teacher and let him prepare the experiment content in advance. The student should memorize the corresponding experiment, familiar with the early experimental instrument. He should ask the teacher to understand when he is not clear. He should do the experiment for every link. If the process of speaking, the students do not understand the place to answer the doubts of the students in Fig.1. Between students 
and students is the same level, they are more daring to ask questions, The students speak more easy to let the rest of the students to understand.

\subsection{Class model inversion}

The traditional teaching model is a teacher in the first place in the classroom to teach knowledge and let students make homework after class. This way of learning is used since China, and get the great achievements, but it is not every good results in training students' autonomous learning ability. Because the student has been a student to depend on the teacher, it will not take the initiative to learn and solve the problem from the different points. Let the students themselves back to the teacher, from the teacher's point of view to think about the problem and there is no dependence. Because he must give others to speak of knowledge from their own efforts, through many related methods of books, put yourself to speak of knowledge, it can not only make others speak, but also to mobilize the enthusiasm of their own to make himself familiar with the knowledge points.
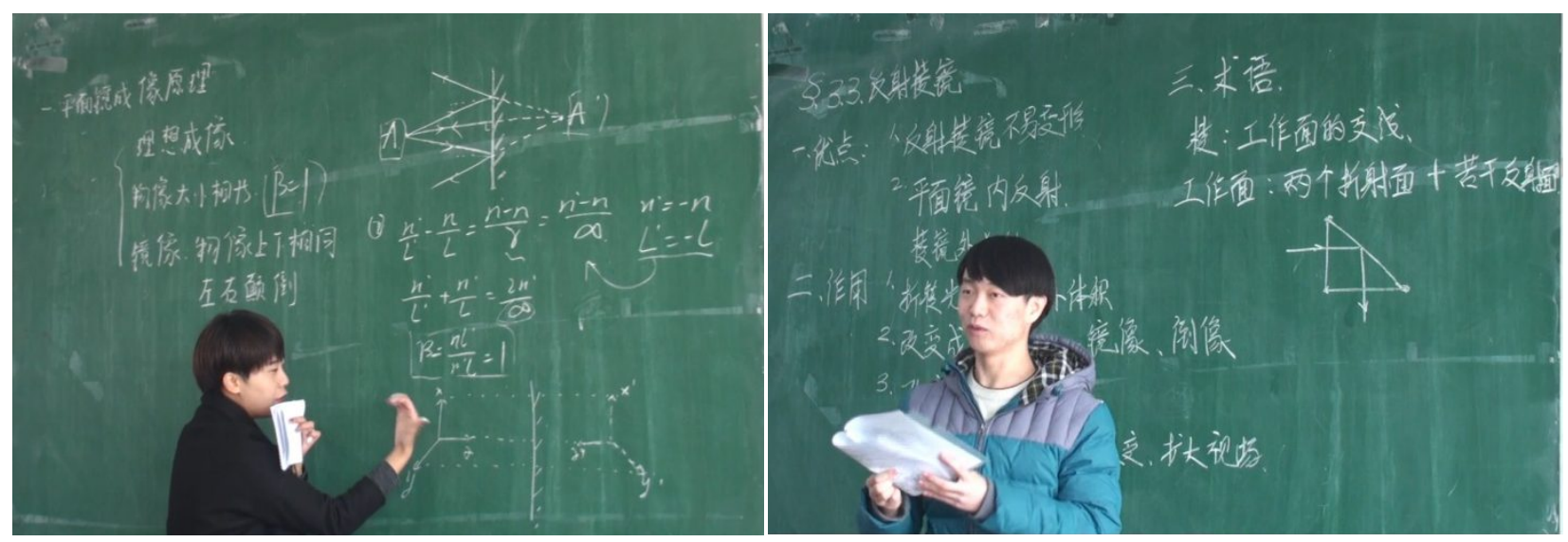

Fig.2 Students speak a lesson as a teacher

we arranged two students to teach knowledge on the platform in Fig.2. Two students are very serious, they speak the knowledge point is very clear. The classroom response is very good, students are very interesting in this model. The advantages of this learning mode create the learning environment which reduce the pressure on students. and let students to explore appropriate learning habits and characteristics of their own, and it can master their learning schedule. This way can mobilize the initiative and enthusiasm of students.

\subsection{Teaching method of students discuss}

Student-centered teaching methods to deal with the problem definition and drive students to learn independently. The problem based on teaching mode is the starting point of teaching, which runs through the process of teaching. The learning begins with the cognition of the problem, and finally solves the problem. The role of teachers and students has undergone great changes, teachers are no longer the main knowledge of the students, but the students' independent learning facilitator. 

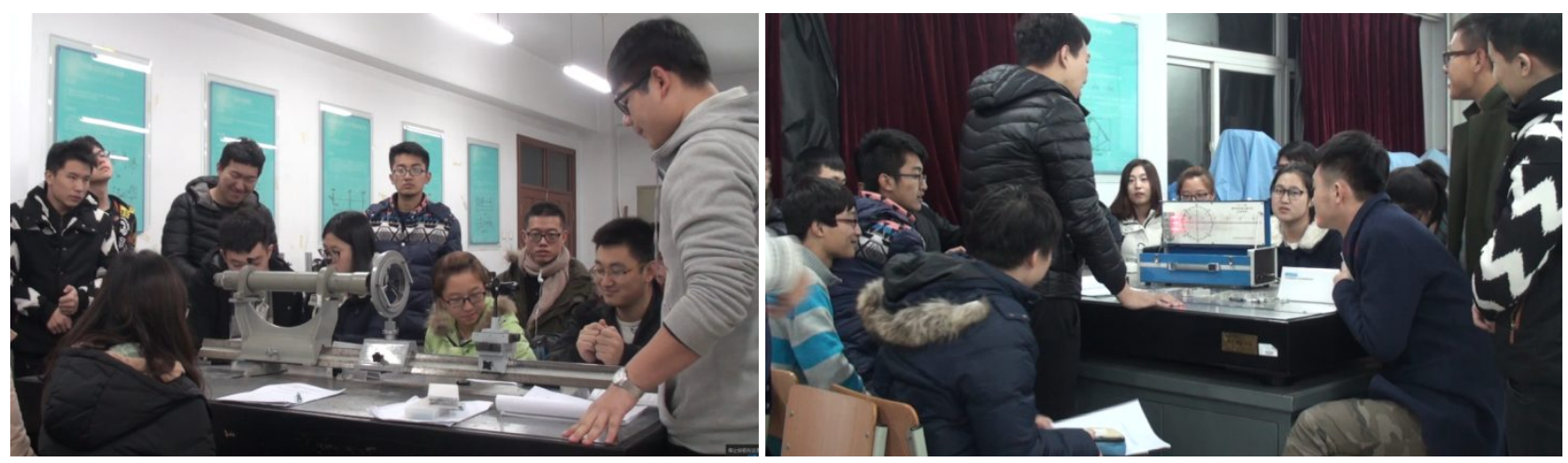

Fig.3 The Students discussion research

The student group discussion research in Fig.3. They carry on the task division of labor, carry out the investigation and study, expand the group discussion and exchange the research results. In the process of continuous construction and re construction of knowledge, they not only find the source of the abstract theory, but also have a new discovery. Cooperative learning on the one hand helps to reduce the cognitive burden of group members. Because of the burden for each individual in the group is often more difficult to cope with, and with the cooperation of team members can make full use of their ability and cleverness, in a collective way to deal with the problem. On the other hand, discussion and argument between team members, promotes the development of advanced thinking ability, team cooperation is helpful to train students' team work spirit and ability, the formation of interpersonal and communication skills, promote learning motivation; At the same time also to form the habit of multi-angle thinking and learning style.

\section{CONCLUSIONS}

The method can make the students get knowledge very well by themselves and give full play to their potential and the subjective initiative. Compared with the previous conventional teaching, the students master the knowledge points more clearly. This method is real and effective, we get good results through a semester of teaching.

\section{REFERENCES}

[1]. Hmelo-Silver, C. E. Problem-based learning: What and how do students learn? Education Psychology Review,16( 3) ,235-266(2004).

[2]. Williamson,S.\& Chang,V. Enhancing the success of SOTL research : A case study using modified problem-based learning in social education, Journal of the Scholarship of Teaching and Learning. 9( 2) ,1-9(2009). [3]. Schmidt, H.G \& Moust, H. C. Factors Affecting Small-Group Tutorial Learning A Review : Research Education Psychology Review. 19( 2) ,19-52(2000). 